\title{
Ultrasonic-assisted unusual four-component synthesis of 7-azolylamino-4,5,6,7-tetrahydroazolo[1,5-a]pyrimidines
}

\author{
Yana I. Sakhno ${ }^{1}$, Maryna V. Murlykina ${ }^{1,2}$, Oleksandr I. Zbruyev ${ }^{1}$, Anton V. Kozyryev ${ }^{1}$, \\ Svetlana V. Shishkina ${ }^{1,2}$, Dmytro Sysoiev ${ }^{3}$, Vladimir I. Musatov ${ }^{1}$, Sergey M. Desenko ${ }^{1,2}$ \\ and Valentyn A. Chebanov ${ }^{*} 1,2$
}

\section{Full Research Paper}

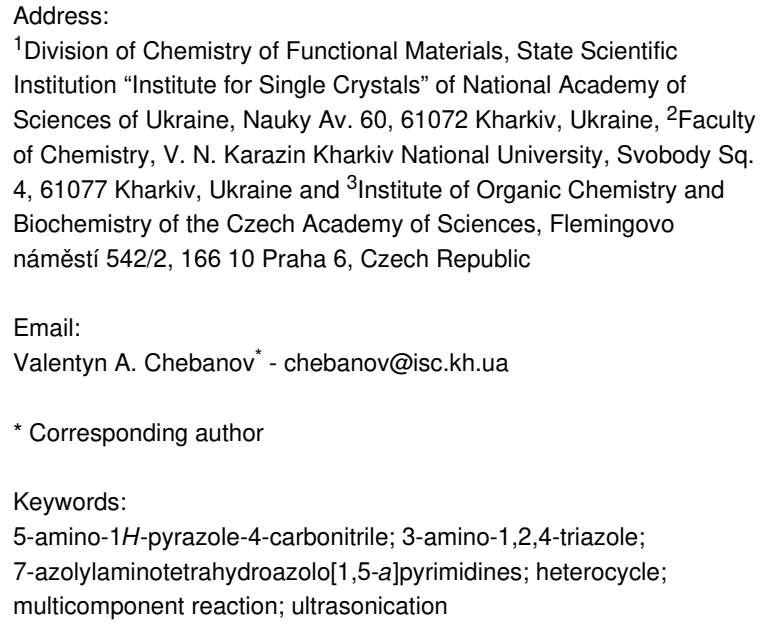

${ }^{1}$ Division of Chemistry of Functional Materials, State Scientific Institution "Institute for Single Crystals" of National Academy of Sciences of Ukraine, Nauky Av. 60, 61072 Kharkiv, Ukraine, ${ }^{2}$ Faculty of Chemistry, V. N. Karazin Kharkiv National University, Svobody Sq. 4, 61077 Kharkiv, Ukraine and ${ }^{3}$ Institute of Organic Chemistry and Biochemistry of the Czech Academy of Sciences, Flemingovo náměstí 542/2, 16610 Praha 6, Czech Republic

Email:

Valentyn A. Chebanov* - chebanov@isc.kh.ua

* Corresponding author

Keywords:

5-amino-1H-pyrazole-4-carbonitrile; 3-amino-1,2,4-triazole;

7-azolylaminotetrahydroazolo[1,5-a]pyrimidines; heterocycle;

multicomponent reaction; ultrasonication \author{
doi:10.3762/bjoc. 16.27 \\ Received: 16 December 2019 \\ Accepted: 19 February 2020 \\ Published: 27 February 2020 \\ Associate Editor: I. Baxendale
}

Beilstein J. Org. Chem. 2020, 16, 281-289.

(c) 2020 Sakhno et al.; licensee Beilstein-Institut. License and terms: see end of document.

\begin{abstract}
Four-component reactions of 3-amino-1,2,4-triazole or 5-amino- $1 H$-pyrazole-4-carbonitrile with aromatic aldehydes and pyruvic acid or its esters under ultrasonication were studied. Unusual for such a reaction type, a cascade of elementary stages led to the formation of 7-azolylaminotetrahydroazolo[1,5-a]pyrimidines.
\end{abstract}

\section{Introduction}

Tetrahydropyrimidines are heterocycles of high pharmacological importance, and they have attracted the attention of medicinal chemists because of their various biological activities [1] Furthermore, tetrahydropyrimidines containing fused azole rings are a privileged class of heterocycles due to their antiviral [2], antitubercular, antitumor [3], antibacterial [4,5], and boneanabolic activities [6,7]. Previously, some tetrahydroazolopyrimidines II (Scheme 1) were synthesized using sequential synthetic routes [8-15], in most cases involving the reduction of the dihydroazolopyrimidines I obtained via well-known reactions of aminoazoles with $\alpha, \beta$-unsaturated ketones [8-11] or via their multicomponent analogues. On the other hand, multicomponent reactions (MCRs) directly leading to tetrahydroazolopyrimidine heterocyclic systems have also been published [4,5,1624]. In particular, multicomponent approaches were described for the synthesis of 7-hydroxytetrahydroazolopyrimidines by the reaction of aminoazoles, aromatic aldehydes, and some carbonyl compounds (Scheme 1, IV and Scheme 2, VI and VIII) 


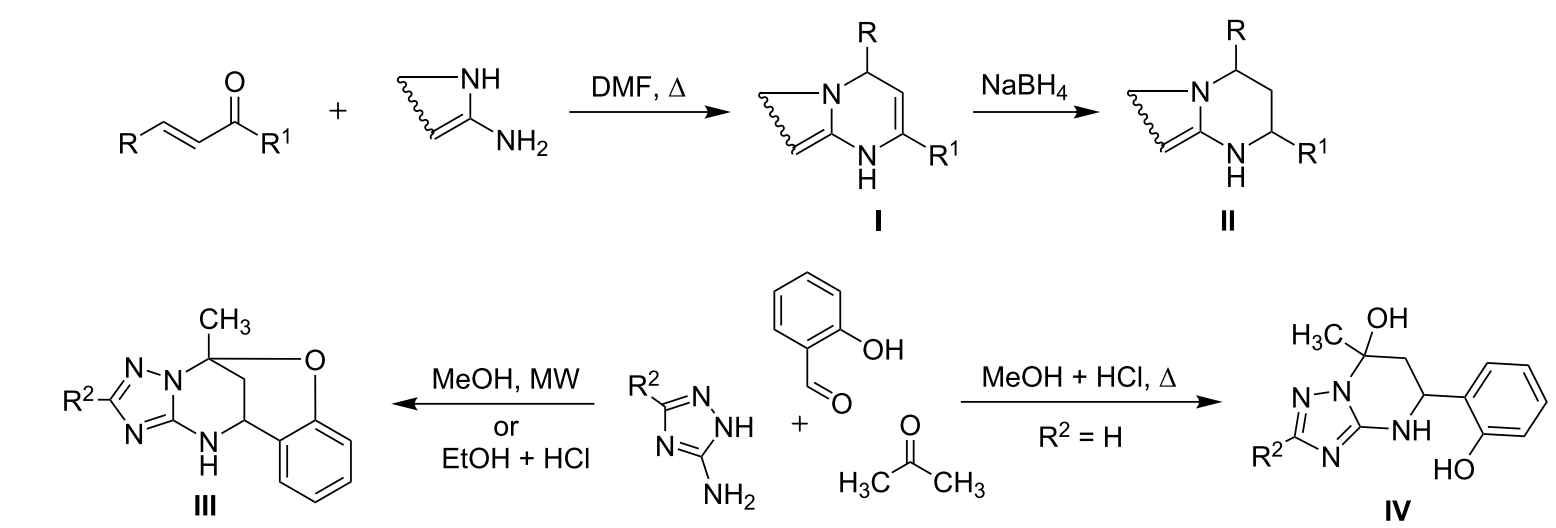

Scheme 1: Synthesis of tetrahydroazolopyrimidine derivatives.<smiles>Nc1ncn[nH]1</smiles><smiles>Nc1nnn[nH]1</smiles><smiles>[R]c1n[nH]c(N)c1[R]</smiles><smiles>NC1CCCCCC1</smiles>

$\mathrm{R}^{1}=\mathrm{H}, \mathrm{Ar} ; \mathrm{R}^{2}=\mathrm{H}$, alkyl, CONHAr

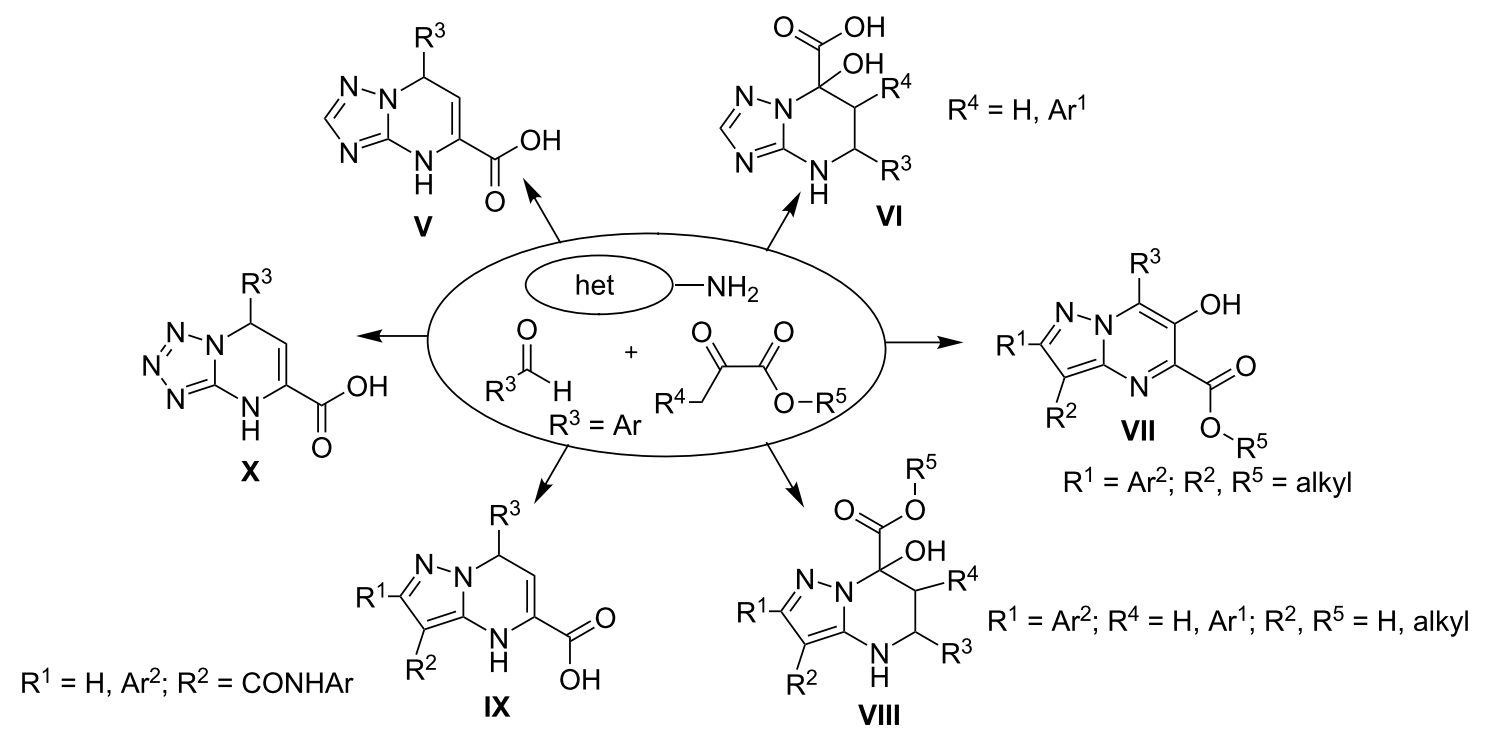

Scheme 2: Various multicomponent reactions involving pyruvic acids (pyruvates) and different $\alpha$-aminoazoles.

[4,5,16-23]. Oxygen-bridged tetrahydroazolopyrimidines III were also obtained via similar MCRs when using salicylic aldehydes, allowing further intermolecular cyclization $[23,24]$.

One of the promising reagents for the synthesis of diverse types of azoloazines by multicomponent and sequential reactions is pyruvic acid, along with its derivatives (Scheme 2). The selectivity of such interactions can be tuned, for example, by application of a condition-based divergence strategy [25], which is based on the variation of solvents, catalysts, and activation methods [16,26-29].
Thus, using nonclassical activation methods such as ultrasonication and microwave irradiation enabled us to develop highly selective procedures for obtaining triazolo-, tetrazolo-, and pyrazolopyrimidines [4,5,16-20,27-29], as well as oxygenbridged tetrahydropyrazolopyrimidines [4,19], furanone [17,30], and pyrrolone derivatives [5,16-18].

Besides the presence of an $\mathrm{OH}$ group in the tetrahydropyrimidine moiety (e.g., Scheme 2, VI and VIII), the formation of heterocycles that are amino-substituted in a similar position is also possible and has been described [31,32]. In particular, the 
reaction of methyl pyruvate and anilines led to the formation of 4-arylamino-substituted tetrahydroquinolines (Scheme 3). To the best of our knowledge, an analogous reaction has not been described for aminoazoles.

We were interested to study reactions similar to the ones shown in Scheme 3, involving aromatic aldehydes and pyruvic acid but using aminoazoles instead of anilines. Therefore, the present work is devoted to the study of multicomponent reactions involving 3-amino-1,2,4-triazole or 5-aminopyrazoles, aromatic aldehydes, and pyruvic acid or its esters under ultrasonication

\section{Results and Discussion}

It was discovered that MCRs involving 3-amino-1,2,4-triazole or 5-amino- $1 \mathrm{H}$-pyrazole-4-carbonitrile with aromatic aldehydes and pyruvic acid or its esters under ultrasonication led to the formation of 4,5,6,7-tetrahydroazolo[1,5-a]pyrimidines 4a-u (Scheme 4) containing an azolylamino substituent in the 7-position via an unusual pseudo four-component reaction, rather than two heterocycles of the types $\mathbf{V}-\mathbf{X}$ (Scheme 2). It should be noted that such a type of MCR, giving previously undescribed 7-azolylamino-substituted tetrahydroazolopyrimidines, is reported for the first time herein.

Thus, using 2 equivalents of 5-aminopyrazole-4-carbonitrile $\mathbf{1 a} / \mathbf{b}$ in MCRs with aromatic aldehydes $\mathbf{2 a}-\mathbf{c}$ and pyruvic acid (3a) in acetic acid at room temperature under ultrasonication for 90 min gave 3-cyano-7-((4-cyano- $1 H$-pyrazol-5-yl)amino)-5aryl-4,5,6,7-tetrahydropyrazolo[1,5- $a$ ]pyrimidine-7-carboxylic acids $4 \mathbf{a}-\mathbf{c}$. There is also the possibility of applying ethyl pyruvate $(\mathbf{3 b})$ instead of pyruvic acid as a reactant in the reaction with 3-substituted-5-aminopyrazole-4-carbonitriles $(\mathrm{R}=\mathrm{H}$, $\left.\mathrm{CH}_{3}\right) \mathbf{1 a} / \mathbf{b}$ and aromatic aldehydes $\mathbf{2 a}-\mathbf{f}$ (ultrasonication in acetic acid at room temperature for $120 \mathrm{~min}$ ). In this case, the corresponding ethyl 3-cyano-7-((4-cyano-3-substituted-1Hpyrazol-5-yl)amino)-2-substituted-5-aryl-4,5,6,7-tetrahydropyrazolo[1,5- $a$ ]pyrimidine-7-carboxylates (substituents $=\mathrm{H}, \mathrm{CH}_{3}$ ) 4d-o were isolated in $45-80 \%$ yields (Scheme 4 , Table 1 ).

The same products were isolated while carrying out this reaction in acetic acid at room temperature with intensive stirring instead of ultrasonic irradiation. However, the reaction time had<smiles>[R]c1ccc(NC2(C)CC(C)(C)Nc3ccc([R])cc3C2(CC(=O)OC)Nc2ccc([R])cc2)cc1</smiles>

Scheme 3: Synthesis of 4-arylamino-substituted tetrahydroquinolines.

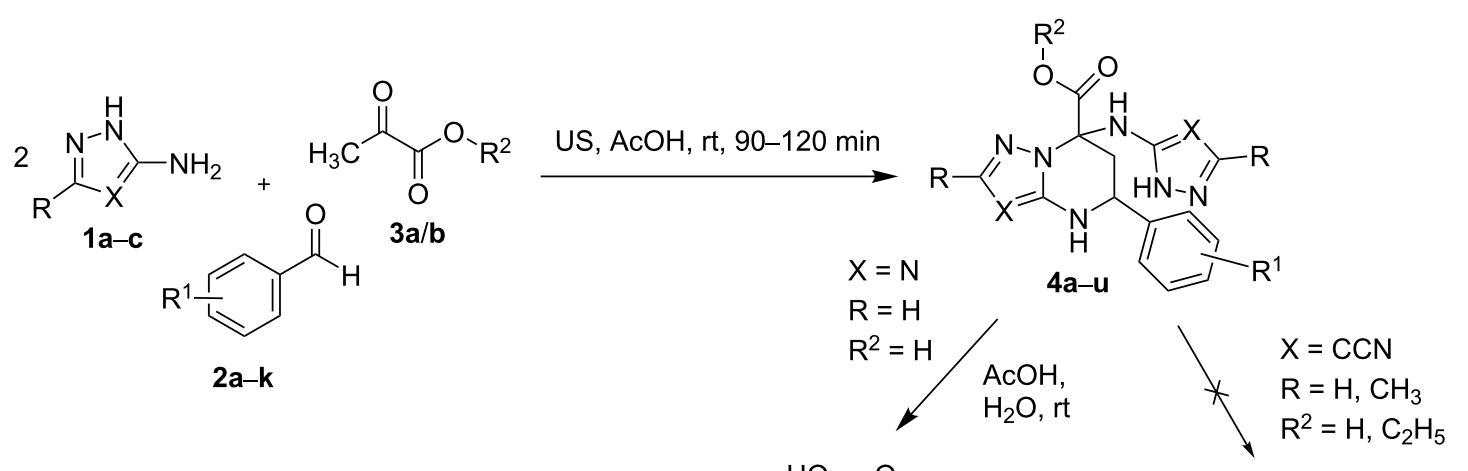<smiles>[R][I]1=CC=C(C2CC(O)(C(=O)O)n3ncnc3N2)C=C1</smiles>

5a-f<smiles>[R]OC(=O)C1(O)CC(c2ccccc2)Nc2c(C#N)c([R])nn21</smiles> 


\begin{tabular}{|c|c|c|c|c|c|c|c|c|c|}
\hline \multirow[b]{2}{*}{1} & \multicolumn{3}{|c|}{ starting material } & \multirow[b]{2}{*}{2} & \multirow[b]{2}{*}{$\mathrm{R}^{2}$} & \multirow[b]{2}{*}{3} & \multirow[t]{2}{*}{ US reaction time (min) } & \multirow{2}{*}{$\begin{array}{c}\text { product } \\
\mathbf{4}\end{array}$} & \multirow[t]{2}{*}{ yield (\%) } \\
\hline & $x$ & $\mathrm{R}$ & $\mathrm{R}^{1}$ & & & & & & \\
\hline $1 a$ & $1-\mathrm{CN}$ & $\mathrm{H}$ & $\mathrm{H}$ & $2 a$ & $\mathrm{H}$ & $3 a$ & 90 & $4 a$ & 76 \\
\hline 1a & $"$ & $\mathrm{H}$ & $4-\mathrm{CH}_{3} \mathrm{O}$ & $2 b$ & $\mathrm{H}$ & $3 a$ & 90 & $4 b$ & 86 \\
\hline $1 a$ & $"$ & $\mathrm{H}$ & 4-Cl & $2 c$ & $\mathrm{H}$ & $3 a$ & 90 & $4 c$ & 75 \\
\hline 1a & $"$ & $\mathrm{H}$ & $4-\mathrm{H}$ & $2 \mathbf{a}$ & $\mathrm{C}_{2} \mathrm{H}_{5}$ & $3 b$ & 120 & $4 d$ & 60 \\
\hline 1a & $"$ & $\mathrm{H}$ & $4-\mathrm{CH}_{3} \mathrm{O}$ & $2 b$ & $\mathrm{C}_{2} \mathrm{H}_{5}$ & $3 b$ & 120 & $4 e$ & 73 \\
\hline $1 a$ & $"$ & $\mathrm{H}$ & 4-Cl & $2 c$ & $\mathrm{C}_{2} \mathrm{H}_{5}$ & $3 b$ & 120 & $4 f$ & 55 \\
\hline $1 a$ & $"$ & $\mathrm{H}$ & $4-\mathrm{Br}$ & $2 d$ & $\mathrm{C}_{2} \mathrm{H}_{5}$ & $3 b$ & 120 & $4 \mathrm{~g}$ & 80 \\
\hline 1a & $"$ & $\mathrm{H}$ & $4-\mathrm{COOCH}_{3}$ & $2 e$ & $\mathrm{C}_{2} \mathrm{H}_{5}$ & $3 b$ & 120 & $4 \mathrm{~h}$ & 64 \\
\hline $1 a$ & $"$ & $\mathrm{H}$ & 4-CN & $2 f$ & $\mathrm{C}_{2} \mathrm{H}_{5}$ & $3 b$ & 120 & $4 \mathbf{i}$ & 53 \\
\hline $1 b$ & $"$ & $\mathrm{CH}_{3}$ & $\mathrm{H}$ & $2 a$ & $\mathrm{C}_{2} \mathrm{H}_{5}$ & $3 b$ & 120 & $4 \mathbf{j}$ & 45 \\
\hline $1 b$ & $"$ & $\mathrm{CH}_{3}$ & $4-\mathrm{CH}_{3} \mathrm{O}$ & $2 b$ & $\mathrm{C}_{2} \mathrm{H}_{5}$ & $3 b$ & 120 & $4 \mathbf{k}$ & 68 \\
\hline $1 b$ & $"$ & $\mathrm{CH}_{3}$ & 4-Cl & $2 c$ & $\mathrm{C}_{2} \mathrm{H}_{5}$ & $3 b$ & 120 & 41 & 55 \\
\hline $1 b$ & $"$ & $\mathrm{CH}_{3}$ & $4-\mathrm{Br}$ & $2 d$ & $\mathrm{C}_{2} \mathrm{H}_{5}$ & $3 b$ & 120 & $4 m$ & 63 \\
\hline $1 b$ & $"$ & $\mathrm{CH}_{3}$ & $4-\mathrm{COOCH}_{3}$ & $2 e$ & $\mathrm{C}_{2} \mathrm{H}_{5}$ & $3 b$ & 120 & $4 n$ & 55 \\
\hline $1 b$ & $"$ & $\mathrm{CH}_{3}$ & 4-CN & $2 f$ & $\mathrm{C}_{2} \mathrm{H}_{5}$ & $3 b$ & 120 & 40 & 47 \\
\hline $1 c$ & $\mathrm{~N}$ & $\mathrm{H}$ & $4-\mathrm{CH}_{3} \mathrm{O}$ & $2 b$ & $\mathrm{H}$ & $3 a$ & 120 & $4 p$ & 60 \\
\hline $1 c$ & $\mathrm{~N}$ & $\mathrm{H}$ & $3-\mathrm{CH}_{3} \mathrm{O}$ & $2 g$ & $\mathrm{H}$ & $3 a$ & 120 & $4 q$ & 65 \\
\hline 1c & $\mathrm{N}$ & $\mathrm{H}$ & $2-\mathrm{CH}_{3} \mathrm{O}$ & $2 \mathrm{~h}$ & $\mathrm{H}$ & $3 a$ & 120 & $4 r$ & 70 \\
\hline $1 c$ & $\mathrm{~N}$ & $\mathrm{H}$ & 4-OH & $2 k$ & $\mathrm{H}$ & $3 a$ & 120 & $4 s$ & 76 \\
\hline $1 c$ & $\mathrm{~N}$ & $\mathrm{H}$ & $3-\mathrm{OH}$ & $2 \mathrm{j}$ & $\mathrm{H}$ & $3 a$ & 120 & $4 t$ & 34 \\
\hline $1 c$ & $\mathrm{~N}$ & $\mathrm{H}$ & $2-\mathrm{OH}$ & $2 \mathbf{i}$ & $\mathrm{H}$ & $3 a$ & 120 & $4 u$ & 49 \\
\hline
\end{tabular}

to be increased to $24 \mathrm{~h}$, and the yields and purity of the compounds $\mathbf{4}$ decreased (as seen via TLC and NMR analysis), obviously due to the worse homogenization and mass transfer compared to ultrasonication.

Literature data [17,26,27,33-35] indicates that 5-aminopyrazoles bearing an electron-withdrawing substituent in the 4-position, such as a carbonitrile group, often behave similar to 3-amino-1,2,4-triazole; therefore, we studied the latter under the same reaction conditions. We showed that the pseudo four-component heterocyclization of two equivalents of 3-amino-1,2,4triazole (1c) with aromatic aldehydes $\mathbf{2 a - f}$ and pyruvic acid (3a) carried out in acetic acid at a room temperature under ultrasonication for $120 \mathrm{~min}$ gave 7-((1H-1,2,4-triazol-5-yl)amino)-5aryl-4,5,6,7-tetrahydro[1,2,4] triazolo[1,5-a]pyrimidine-7carboxylic acids $\mathbf{4 p - u}$ in $34-76 \%$ yields (Scheme 4). In contrast to pyrazolyl-substituted pyrazolo[1,5- $a$ ]pyrimidine-7-carboxylic

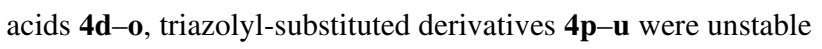
in protic solvents in the presence of water, and especially upon increasing the temperature gradually transformed into 7-hydroxytriazolo[1,5- $a$ ]pyrimidines 5a-f, which had been obtained earlier [5] by the three-component reaction of starting materials 1c, 2a-f, and 3a (HOAc, $65^{\circ} \mathrm{C}, 48 \mathrm{~h}$ ). This instability complicated the isolation and characterization of the hetero- cycles $4 \mathbf{p}-\mathbf{u}$. The condensation of compounds $1 \mathbf{c}, \mathbf{2 a}-\mathbf{f}$, and $\mathbf{3 a}$ in dry DMF under otherwise identical conditions was a way to avoid the rapid conversion of triazolyl derivatives $\mathbf{4 p - u}$ into 7-hydroxytriazolo[1,5- $a$ ]pyrimidines 5a-f and to isolate the heterocycles $\mathbf{4 p - u}$, but in lower yields in comparison to the reaction in acetic acid.

We consequently screened various condensation conditions, specifically by applying different temperatures in the range of 0-110 ${ }^{\circ} \mathrm{C}$ (both with the help of conventional heating and microwave irradiation) and by using different solvents and catalysts, such as HOAc, DMSO, primary alcohols with and without the presence of $\mathrm{HCl}, \mathrm{Yb}(\mathrm{OTf})_{3}$, or $\mathrm{Et}_{3} \mathrm{~N}$. In all these cases,

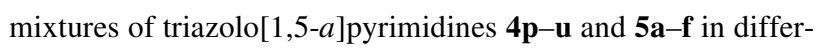
ent ratios (the content of compounds $\mathbf{5 a}-\mathbf{f}$ increased with the elevation of temperature and time) with impurities of starting reagents and unidentified compounds were obtained.

In contrast to tetrahydropyrimidines $\mathbf{4 p - u}$, containing triazolyl fragments, our attempts to obtain compounds 6 from pyrazolyl derivatives $\mathbf{4 b} / \mathbf{c} / \mathbf{e} / \mathbf{f}$ were unsuccessful. In particular, under the same conditions (prolonged stirring in acetic acid at temperatures up to $70{ }^{\circ} \mathrm{C}$ ), the starting tetrahydropyrazolopyrimidines $\mathbf{4 b} / \mathbf{c} / \mathbf{e} / \mathbf{f}$ remained unchanged. Then, it was established that 
compound 4e remained stable under refluxing in acetic acid for $60 \mathrm{~min}$, while heating for $120-180 \mathrm{~min}$ led to its decomposition. At the same time, compound $\mathbf{4 b}$, after refluxing in acetic acid for ca. $120 \mathrm{~min}$, was converted into 3-cyano-7-(4-methoxyphenyl)-4,7-dihydropyrazolo[1,5-a]pyrimidine-5-carboxylic acid (7, yield $35 \%)$. The same carboxylic acid 7 was obtained by counter synthesis through a three-component reaction involving 5-aminopyrazole-4-carbonitrile (1a), 4-methoxybenzaldehyde (2b), and pyruvic acid (3a) under heating at reflux in acetic acid for $240 \mathrm{~min}$ (yield $28 \%$ ) or through two-component heterocyclization of 5-aminopyrazole 1a and $p$-methoxybenzylidenepyruvic acid (8, obtained from $p$-methoxybenzaldehyde and pyruvic acid) under the same conditions in a much shorter reaction time $(10 \mathrm{~min})$ with $66 \%$ yield (Scheme 5).

The results presented above indicate that the reaction possibly proceeded under kinetic and thermodynamic control, depending on the conditions. In particular, ultrasonication of the starting materials 1a, 2b, and 3a for $90 \mathrm{~min}$ at room temperature provided the kinetically controlled azolyltetrahydropyrimidine derivative $\mathbf{4 b}$ (Scheme 4), while high-temperature treatment of the same starting materials (HOAc, refluxing at $118{ }^{\circ} \mathrm{C}$ for $240 \mathrm{~min}$ ) yielded the thermodynamically preferred dihydropyrazolopyrimidine-5-carboxylic acid 7 (Scheme 5).

The most probable pathway A (Scheme 6) to compounds 4 includes initial formation of the corresponding azomethines 9 and 10. A similar pathway was previously described and discussed in publications $[31,32]$. We cannot exclude other mechanisms, for example, via arylidenepyruvic acids (esters) 11 formed by water elimination from appropriate aldols (pathway B). However, our attempts to synthesize compound $\mathbf{4}$ by direct reaction of unsaturated acid $\mathbf{8}$ and aminoazole 1a under different conditions (ultrasonic activation and conventional heating) were unsuccessful, and only dihydropyrimidine 7 was obtained.

\section{Structure elucidation}

The purity and structures of the synthesized heterocycles were determined using elemental analysis, mass spectrometry, NMR spectroscopy (1D and 2D NMR experiments), and X-ray diffraction analysis. The signals in the ${ }^{1} \mathrm{H}$ and ${ }^{13} \mathrm{C}$ NMR spectra of some of the compounds 4 were duplicated. This could have been caused by two reasons, namely by free rotation of the azolyl fragment in the position 7 or by the presence of a second diastereomer. To establish the reason of duplication, NMR spectra were recorded at different temperatures. As the temperature was increased from $25^{\circ} \mathrm{C}$ to $130{ }^{\circ} \mathrm{C}$, the peaks were still duplicated, proving the presence of two diastereomers.

The ${ }^{1} \mathrm{H}$ NMR spectra of $\mathbf{4 a - 0}$ exhibited three signals of an AMX system for the tetrahydropyrimidine ring (about 2.27-2.48 ppm, 3.03-3.25 ppm, and 4.52-4.83 ppm), three signals for protons of the NH groups (ca. 7.85-8.13 ppm for the pyrimidine $\mathrm{NH}, 6.90-7.21 \mathrm{ppm}$ for the $\mathrm{NH}$ pyrazolyl moiety, and 11.79-12.07 ppm for the aminopyrazole moiety), a $\mathrm{CH}$ signal of the proton at position 2 of the pyrazolopyrimidine, signals of the aryl ring at 7.54-8.34 ppm, and signals corresponding to the alkyl substituent.

The ${ }^{1} \mathrm{H}$ NMR spectra of $\mathbf{4 a}-\mathbf{c} / \mathbf{j} / \mathbf{k} / \mathbf{o}$ showed a double set of signals for the AMX system of the tetrahydropyrimidine ring, the $\mathrm{NH}$ protons, and the protons of the $\mathrm{CH}_{2} \mathrm{CH}_{3}$ moiety (in the case of esters) due to the presence of two isomers of 4 .

The ${ }^{1} \mathrm{H}$ NMR and ${ }^{13} \mathrm{C}$ NMR spectra of triazolyl derivatives $\mathbf{4 p - u}$ were more complicated, both due to the duplication of the

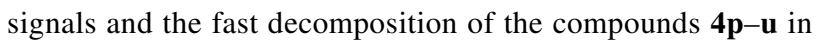
solutions. Therefore, 2D NMR and, in some cases, ${ }^{13} \mathrm{C}$ NMR spectra were overcrowded and uninformative. Particularly, tetrahydropyrimidines $\mathbf{4} \mathbf{s}-\mathbf{u}$ with hydroxy substituent in the aryl ring happened to be less stable than the derivatives $\mathbf{4 p - r}$ with

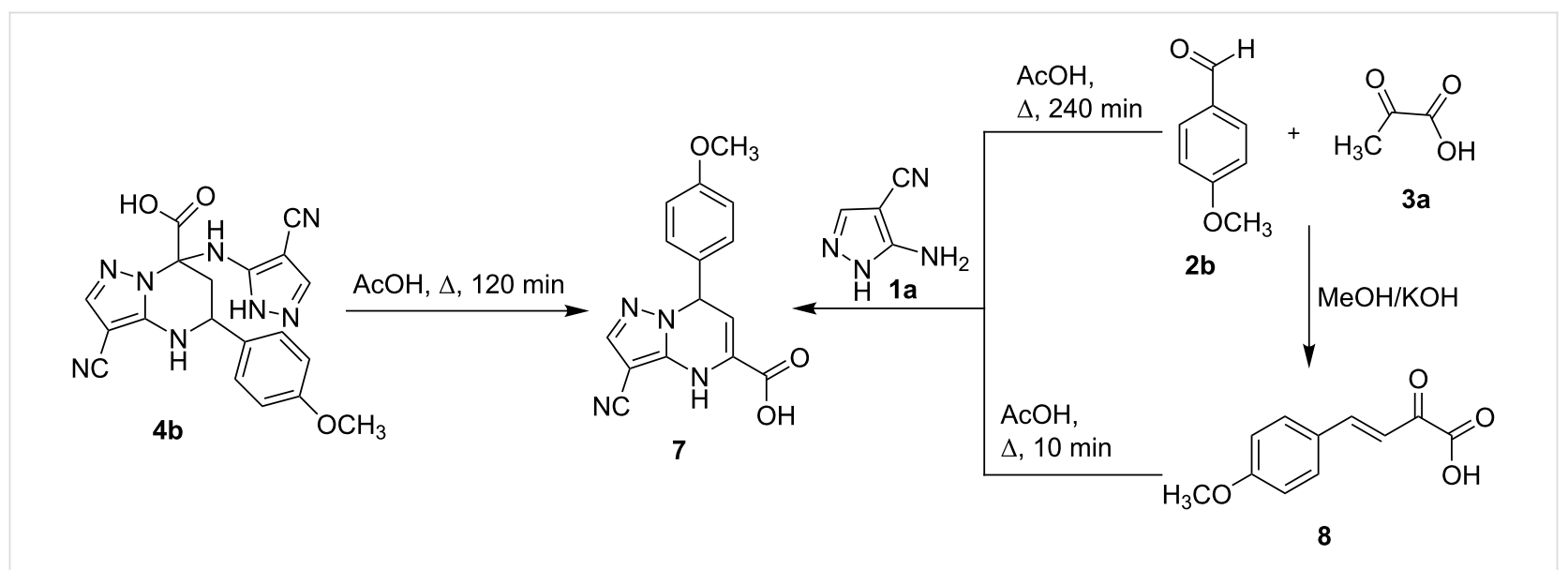




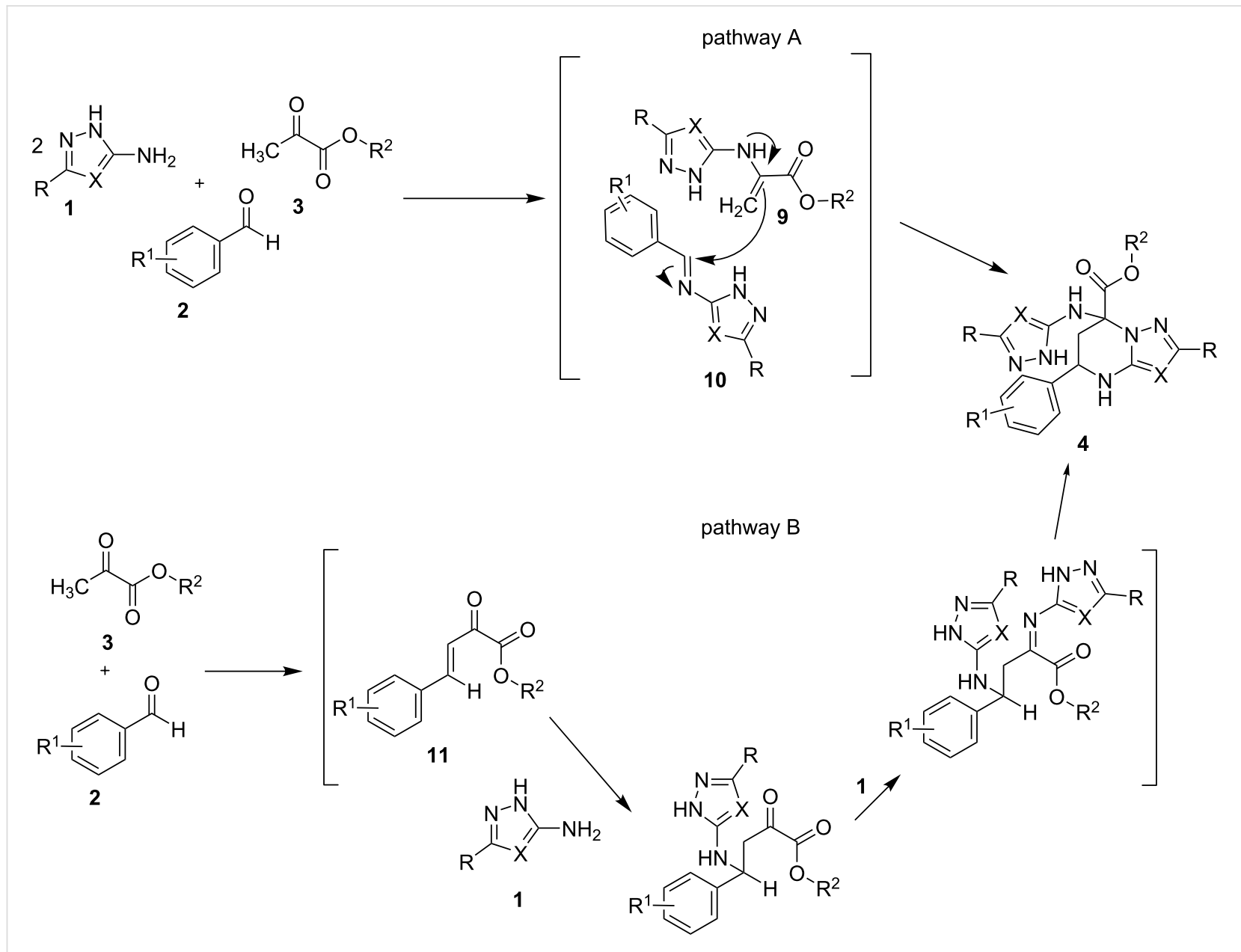

Scheme 6: Proposed reaction mechanism

the methoxy group; this explains the absence of ${ }^{13} \mathrm{C}$ NMR spectra for compounds $4 \mathbf{t} / \mathbf{u}$ in our work.

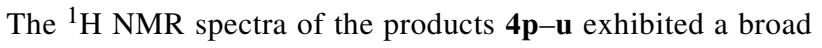
singlet for the triazole $\mathrm{NH}$ and carboxyl groups at ca. 13.10-13.30 ppm, a broad singlet for the phenolic $\mathrm{OH}$ group at 9.40-9.70 ppm (for compounds 4s-u), singlets of pyrimidine $\mathrm{NH}$ and $\mathrm{CH}$ groups of the triazolyl and triazole fragments in the interval of 7.31-7.91 ppm, a singlet of the triazolylamino group at 7.23-7.35 ppm, a multiplet for the $\mathrm{CH}$ proton in position 5 at 5.10-5.25 ppm (for the derivatives $4 \mathbf{r} / \mathbf{u}$ with ortho-substituent in the aryl ring) or at 4.60-4.90 ppm for the compounds $\mathbf{4 p} / \mathbf{q} / \mathbf{s} / \mathbf{t}$, multiplets for the $\mathrm{CH}_{2}$ group in position 6 at 2.90-3.60 ppm and 2.11-2.50 ppm, and multiplets of aromatic protons at $6.65-7.45 \mathrm{ppm}$.

The spectral data obtained for the tetrahydropyrimidines $\mathbf{4}$ most likely corresponded to the possible regioisomers $\mathbf{A}$ and $\mathbf{B}$ (Figure 1). Additional NOESY experiments, in particular for compound $\mathbf{4 k}$, showed the presence of cross-peaks between the
$\mathrm{CH}$ proton at position 5 with the pyrimidine $\mathrm{NH}$ group and cross-peaks of the $\mathrm{NH}$ group with protons of the aromatic system, thus excluding structure B (Figure 1).

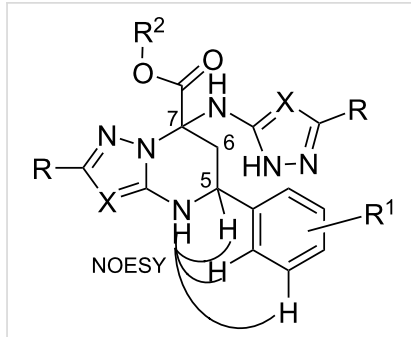

A<smiles></smiles>

$B^{2}$
Figure 1: Alternative structures $\mathbf{A}$ and $\mathbf{B}$ for the tetrahydroazolopyrimidines 4.

Eventually, the structure of tetrahydropyrimidines $\mathbf{4}$ was proven by X-ray analysis carried out for a single crystal of one diastereomer of compound $\mathbf{4 g}$, which allowed assignment of the structure as ethyl 5-(4-bromophenyl)-3-cyano-7-((4-cyano- $1 H$ - 
pyrazol-5-yl)amino)-4,5,6,7-tetrahydropyrazolo[1,5-a]pyrimidine-7-carboxylate (Figure 2).

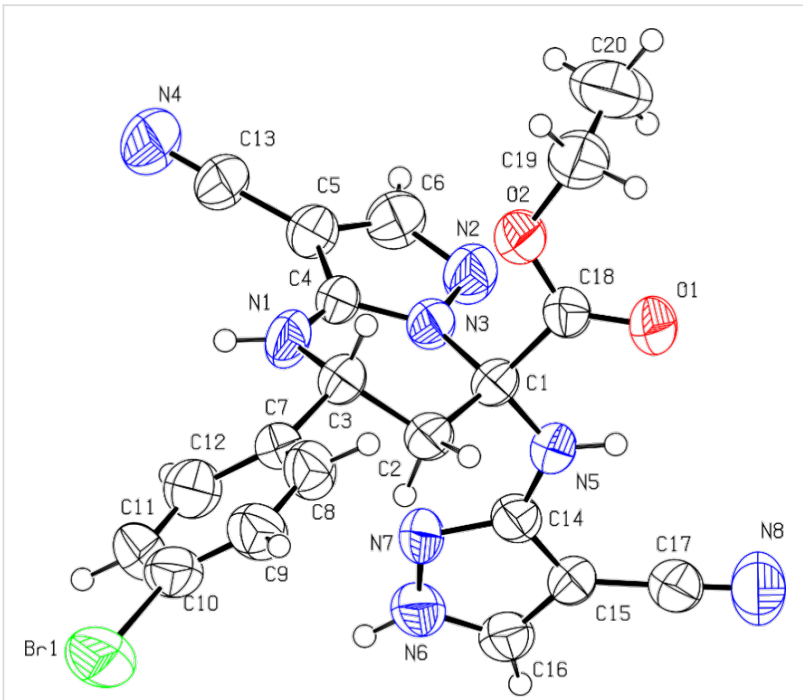

Figure 2: Molecular structure of ethyl 5-(4-bromophenyl)-3-cyano-7((4-cyano-1H-pyrazol-5-yl)amino)-4,5,6,7-tetrahydropyrazolo[1,5a]pyrimidine-7-carboxylate $(\mathbf{4 g})$ obtained from X-ray diffraction data.

Compound $\mathbf{4 g}$ existed as a solvate with acetonitrile in the crystal lattice. The tetrahydropyrimidine ring adopted a halfchair conformation (the puckering parameters [36] were: $\mathrm{S}=$ $0.70, \Theta=25.6^{\circ}, \Psi=21.6^{\circ}$ ). Deviations of the $\mathrm{C} 2$ and $\mathrm{C} 3$ atoms from the mean-plane of the remaining atoms of this ring were $-0.26 \AA$ and $0.35 \AA$, respectively. The phenyl substituent was located in an equatorial position and was slightly turned in relation to the N1-C3 endocyclic bond (the C4-N1-C3-C7 and $\mathrm{N} 1-\mathrm{C} 3-\mathrm{C} 7-\mathrm{C} 12$ torsion angles were $-163.6(4)^{\circ}$ and $19.7(7)^{\circ}$, respectively). Short intramolecular contacts appeared: the $\mathrm{H} 1(\mathrm{~N}) \cdots \mathrm{H} 12$ distance was $2.10 \AA$ and the van der Waals radii sum [37] was $2.34 \AA$, the $\mathrm{H} \cdots \mathrm{N} 1$ distance was $2.55 \AA$ (and the van der Waals radii sum was $2.67 \AA$ ), while the $\mathrm{H} 1 \cdots \mathrm{C} 12$ distance was $2.60 \AA$, with a van der Waals radii sum of $2.87 \AA$. The two vicinal substituents at the $\mathrm{C} 1$ atom had different orientations in relation to the partially saturated cycle: the ester substituent was in an axial position, while the other substituent was found in an equatorial position (the $\mathrm{C} 4-\mathrm{N} 3-\mathrm{C} 1-\mathrm{C} 18$ and $\mathrm{C} 4-\mathrm{N} 3-\mathrm{C} 1-\mathrm{N} 5$ torsion angles were $-104.0(5)^{\circ}$ and $139.6(5)^{\circ}$, respectively). The carboxylic acid fragment was turned in relation to the N3-C1 endocyclic bond (the N3-C1-C18-O1 torsion angle was $\left.-131.4(5)^{\circ}\right)$. The ethyl group was located in an ap position to the $\mathrm{C} 1-\mathrm{C} 18$ bond and was almost orthogonal to the $\mathrm{C} 18-\mathrm{O} 2$ bond (the $\mathrm{C} 1-\mathrm{C} 18-\mathrm{O} 2-\mathrm{C} 19$ and $\mathrm{C} 18-\mathrm{O} 2-\mathrm{C} 19-\mathrm{C} 20$ torsion angles were $-175.0(4)^{\circ}$ and $85.1(7)^{\circ}$, respectively). The planar cyanopyrazolimino substituent was turned significantly to the $\mathrm{N} 3-\mathrm{C} 1$ endocyclic bond (the N3-C1-N5-C14 torsion angle was $\left.-57.5(6)^{\circ}\right)$.
In the crystal phase, molecules $\mathbf{4} \mathbf{g}$ formed centrosymmetric dimers due to the $\mathrm{N} 1-\mathrm{H} \cdots \mathrm{N} 4$ intermolecular hydrogen bonds $\left(1 \mathrm{x}, 1 \mathrm{y}, 2 \mathrm{z} ; \mathrm{H} \cdots \mathrm{N} 2.22 \AA, \mathrm{N}-\mathrm{H} \cdots \mathrm{N} 164^{\circ}\right)$. The dimers were bound by a N6-H‥O1 intermolecular hydrogen bond (x 1, y, z; $\mathrm{H} \cdots \mathrm{O} 2.16 \AA, \mathrm{N}-\mathrm{H} \cdots \mathrm{O} 162^{\circ}$ ), forming chains along the [100] crystallographic direction (Figure 3 ).

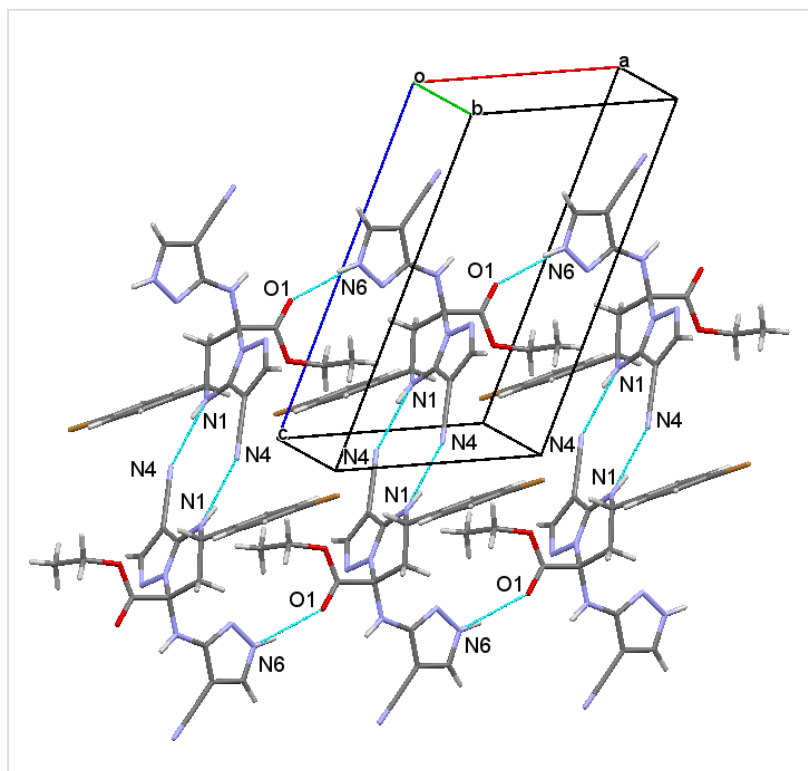

Figure 3: Chains of $\mathbf{4 g}$ molecules in the crystal phase.

\section{Conclusion}

In this study we disclosed a new direction for the multicomponent reaction of 5-aminopyrazole-4-carbonitriles or 3-amino1,2,4-triazole with pyruvic acid or ethyl pyruvate and aromatic aldehydes under ultrasonication, leading to 7-azolylamino4,5,6,7-tetrahydroazolo[1,5-a]pyrimidines via a cascade of elementary stages that is unusual for such transformations. Thus, we extended the molecular diversity of the compounds obtained by introducing an additional azolyl substituent to the pyrimidine ring.

\section{Supporting Information}

\section{Supporting Information File 1}

Experimental and analytical data as well as X-ray crystallographic information.

[https://www.beilstein-journals.org/bjoc/content/ supplementary/1860-5397-16-27-S1.pdf]

\section{Supporting Information File 2}

${ }^{1} \mathrm{H}$ and ${ }^{13} \mathrm{C}$ NMR spectra.

[https://www.beilstein-journals.org/bjoc/content/ supplementary/1860-5397-16-27-S2.pdf] 


\section{Funding}

The authors thank the National Academy of Sciences of Ukraine for financial support in the frame of the projects "Creation of modern bases for obtaining and analyzing substances and components of materials for pharmaceutical purposes" (0119U100727) and "Investigation of structural features of nitrogen containing heterocycles with potential biological activity" (0119U100716). M. Murlykina was supported by the Grant of National Academy of Sciences of Ukraine for young scientists' research laboratories and groups (0118U100275).

\section{ORCID ${ }^{\circledR}$ iDs}

Sergey M. Desenko - https://orcid.org/0000-0001-8914-3232 Valentyn A. Chebanov - https://orcid.org/0000-0001-7564-778X

\section{References}

1. Sepehri, S.; Sanchez, H. P.; Fassihi, A. J. Pharm. Pharm. Sci. 2015, 18, 1-52. doi:10.18433/j3q01v

2. Yu, W.; Goddard, C.; Clearfield, E.; Mills, C.; Xiao, T.; Guo, H.; Morrey, J. D.; Motter, N. E.; Zhao, K.; Block, T. M.; Cuconati, A.; Xu, X. J. Med. Chem. 2011, 54, 5660-5670. doi:10.1021/jm200696v

3. Hassan, A. Y.; Sarg, M. T.; Bayoumi, A. H.; El-Deeb, M. A. J. Heterocycl. Chem. 2018, 55, 1450-1478. doi:10.1002/jhet.3184

4. Murlykina, M. V.; Sakhno, Y. I.; Desenko, S. M.; Konovalova, I. S.; Shishkin, O. V.; Sysoiev, D. A.; Kornet, M. N.; Chebanov, V. A. Tetrahedron 2013, 69, 9261-9269. doi:10.1016/j.tet.2013.08.055

5. Murlykina, M. V.; Sakhno, Y. I.; Desenko, S. M.; Shishkina, S. V.; Shishkin, O. V.; Sysoiev, D. O.; Kornet, M. N.; Schols, D.; Goeman, J. L.; Van der Eycken, J.; Van der Eycken, E. V.; Chebanov, V. A. Eur. J. Org. Chem. 2015, 4481-4492. doi:10.1002/ejoc.201500469

6. Yoshida, M.; Mori, A.; Morimoto, S.; Kotani, E.; Oka, M.; Notoya, K.; Makino, H.; Ono, M.; Shirasaki, M.; Tada, N.; Fujita, H.; Ban, J.; Ikeda, Y.; Kawamoto, T.; Goto, M.; Kimura, H.; Baba, A.; Yasuma, T. Bioorg. Med. Chem. 2011, 19, 1881-1894. doi:10.1016/j.bmc.2011.02.001

7. Yoshida, M.; Mori, A.; Kotani, E.; Oka, M.; Makino, H.; Fujita, H.; Ban, J.; Ikeda, Y.; Kawamoto, T.; Goto, M.; Kimura, H.; Baba, A.; Yasuma, T. J. Med. Chem. 2011, 54, 1430-1440. doi:10.1021/jm101452x

8. Desenko, S. M.; Shishkin, O. V.; Orlov, V. D.; Lipson, V. V.; Lindeman, S. V.; Struchkov, Y. T. Chem. Heterocycl. Compd. (N. Y., NY, U. S.) 1994, 30, 851-855. doi:10.1007/bf01169645

9. Kolosov, M. A.; Shvets, E. H.; Manuenkov, D. A.; Vlasenko, S. A.; Omelchenko, I. V.; Shishkina, S. V.; Orlov, V. D. Tetrahedron Lett. 2017, 58, 1207-1210. doi:10.1016/j.tetlet.2017.02.035

10. Desenko, S. M.; Gladkov, E. S.; Komykhov, S. A.; Shishkin, O. V.; Orlov, V. D. Chem. Heterocycl. Compd. (N. Y., NY, U. S.) 2001, 37, 747-754. doi:10.1023/a:1011925631511

11. Desenko, S. M.; Orlov, V. D.; Lipson, V. V. Chem. Heterocycl. Compd. (N. Y., NY, U. S.) 1990, 26, 1362-1366. doi:10.1007/bf00473964

12. Bellec, C.; Lhommet, G. J. Heterocycl. Chem. 1995, 32, 1793-1800. doi:10.1002/jhet.5570320621
13. Zemlyanaya, N. I.; Karnozhitskaya, T. M.; Musatov, V. I.; Konovalova, I. S.; Shishkina, S. V.; Lipson, V. V. Russ. J. Org. Chem. 2018, 54, 1241-1249. doi:10.1134/s1070428018080201

14. Lipson, V. V.; Karnozhitskaya, T. M.; Shishkina, S. V.; Shishkin, O. V.; Turov, A. V. Russ. Chem. Bull. 2009, 58, 1441-1444. doi:10.1007/s11172-009-0193-1

15. Bartashevich, E. V.; Plekhanov, P. V.; Rusinov, G. L.; Potemkin, V. A.; Belik, A. V.; Chupakhin, O. N. Russ. Chem. Bull. 1999, 48, 1553-1557. doi:10.1007/bf02496411

16. Sakhno, Y. I.; Desenko, S. M.; Shishkina, S. V.; Shishkin, O. V.; Sysoyev, D. O.; Groth, U.; Kappe, C. O.; Chebanov, V. A. Tetrahedron 2008, 64, 11041-11049. doi:10.1016/j.tet.2008.09.089

17. Sakhno, Y. I.; Shishkina, S. V.; Shishkin, O. V.; Musatov, V. I.; Vashchenko, E. V.; Desenko, S. M.; Chebanov, V. A. Mol. Diversity 2010, 14, 523-531. doi:10.1007/s11030-010-9226-9

18. Murlykina, M. V.; Sakhno, Ya. I.; Desenko, S. M.; Chebanov, V. A. In Heterocyclic compounds chemistry. Recent aspects; Kartsev, V. G., Ed.; ICSPF Press: Moscow, Russia, 2014; pp 318-324.

19. Sakhno, Y. I.; Murlykina, M. V.; Morozova, A. D.; Kozyryev, A. V.; Chebanov, V. A. Fr.-Ukr. J. Chem. 2015, 3, 1-20. doi:10.17721/fujcv3i2p1-20

20. Sakhno, Y. I.; Kozyryev, A. V.; Desenko, S. M.; Shishkina, S. V.; Musatov, V. I.; Sysoiev, D. O.; Chebanov, V. A. Tetrahedron 2018, 74, 564-571. doi:10.1016/j.tet.2017.12.031

21. Komykhov, S. A.; Bondarenko, A. A.; Musatov, V. I.; Diachkov, M. V.; Gorobets, N. Y.; Desenko, S. M.

Chem. Heterocycl. Compd. (N. Y., NY, U. S.) 2017, 53, 378-380. doi:10.1007/s10593-017-2059-z

22. Světlík, J.; Kettmann, V. Tetrahedron Lett. 2011, 52, 1062-1066. doi:10.1016/j.tetlet.2010.12.051

23. Gorobets, N. Y.; Sedash, Y. V.; Ostras, K. S.; Zaremba, O. V.; Shishkina, S. V.; Baumer, V. N.; Shishkin, O. V.; Kovalenko, S. M.; Desenko, S. M.; Van der Eycken, E. V. Tetrahedron Lett. 2010, 51, 2095-2098. doi:10.1016/j.tetlet.2010.02.045

24. Gümüş, M. K.; Gorobets, N. Y.; Sedash, Y. V.; Chebanov, V. A.; Desenko, S. M. Chem. Heterocycl. Compd. (N. Y., NY, U. S.) 2017, 53, 1261-1267. doi:10.1007/s10593-018-2204-3

25. Ruijter, E.; Scheffelaar, R.; Orru, R. V. A. Angew. Chem., Int. Ed. 2011, 50, 6234-6246. doi:10.1002/anie.201006515

26. Chebanov, V.; Gura, K.; Desenko, S. Aminoazoles as Key Reagents in Multicomponent Heterocyclizations. In Synthesis of Heterocycles via Multicomponent Reactions I; Orru, R.; Ruijter, E., Eds.; Top. Heterocycl. Chem., Vol. 23; 2010; pp 41-84. doi:10.1007/7081_2009_21

27. Chebanov, V. A.; Sakhno, Y. I.; Desenko, S. M.; Chernenko, V. N.; Musatov, V. I.; Shishkina, S. V.; Shishkin, O. V.; Kappe, C. O. Tetrahedron 2007, 63, 1229-1242. doi:10.1016/j.tet.2006.11.048

28. Chebanov, V. A.; Sakhno, Y. I.; Desenko, S. M. Ultrason. Sonochem. 2012, 19, 707-709. doi:10.1016/j.ultsonch.2011.08.003

29. Murlykina, M. V.; Morozova, A. D.; Zviagin, I. M.; Sakhno, Y. I.; Desenko, S. M.; Chebanov, V. A. Front. Chem. (Lausanne, Switz.) 2018, 6, No. 527. doi:10.3389/fchem.2018.00527

30. Morozova, A. D.; Muravyova, E. A.; Shishkina, S. V.; Sysoiev, D.; Glasnov, T.; Musatov, V. I.; Desenko, S. M.; Chebanov, V. A. Chem. Heterocycl. Compd. 2019, 55, 78-89. doi:10.1007/s10593-019-02422-8

31. Luo, C.; Huang, Y. J. Am. Chem. Soc. 2013, 135, 8193-8196. doi:10.1021/ja4040945

32. Tapia, I.; Alcazar, V.; Grande, M.; Moran, J. R. Tetrahedron 1988, 44, 5113-5116. doi:10.1016/s0040-4020(01)86016-6 
33. Chebanov, V. A.; Desenko, S. M. Diversity-Oriented Synth. 2014, 1 , 43-63. doi:10.2478/dos-2014-0003

34. Chebanov, V. A.; Saraev, V. E.; Shishkina, S. V.; Shishkin, O. V.; Musatov, V. I.; Desenko, S. M. Eur. J. Org. Chem. 2012, 5515-5524. doi:10.1002/ejoc.201200669

35. Muravyova, E. A.; Desenko, S. M.; Rudenko, R. V.; Shishkina, S. V.; Shishkin, O. V.; Sen'ko, Y. V.; Vashchenko, E. V.; Chebanov, V. A. Tetrahedron 2011, 67, 9389-9400. doi:10.1016/j.tet.2011.09.138

36. Zefirov, N. S.; Palyulin, V. A.; Dashevskaya, E. E. J. Phys. Org. Chem. 1990, 3, 147-158. doi:10.1002/poc.610030304

37. Zefirov, Yu. V. Kristallographiya 1997, 42, 936-958.

\section{License and Terms}

This is an Open Access article under the terms of the Creative Commons Attribution License

(https://creativecommons.org/licenses/by/4.0). Please note that the reuse, redistribution and reproduction in particular requires that the authors and source are credited.

The license is subject to the Beilstein Journal of Organic Chemistry terms and conditions:

(https://www.beilstein-journals.org/bjoc)

The definitive version of this article is the electronic one which can be found at: doi:10.3762/bjoc. 16.27 